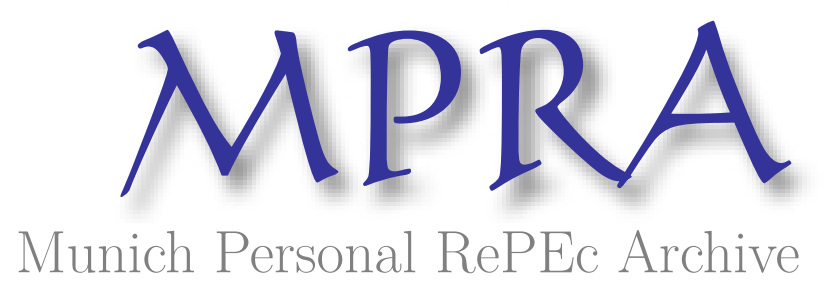

\title{
VECM estimations of the PPP reversion rate revisited: the conventional role of relative price adjustment restored
}

Kim, Hyeongwoo

Auburn University

August 2011

Online at https://mpra.ub.uni-muenchen.de/33005/

MPRA Paper No. 33005, posted 26 Aug 2011 18:48 UTC 


\title{
VECM Estimations of the PPP Reversion Rate Revisited*
}

\author{
Hyeongwoo $\mathrm{Kim}^{\dagger}$ \\ Auburn University
}

April 2011

\begin{abstract}
Cheung et al. (2004) use a vector error correction model (VECM) for the current float nominal exchange rate and the relative price data and claim that the sluggish Purchasing Power Parity (PPP) reversion is primarily driven by the nominal exchange rate, not by relative price adjustment, which is at odds with the conventional sticky-price models. Our major findings are as follows. First, we suggest cases where VECMs are of limited usefulness even when all the variables in the system are not weakly exogenous. Second, using century-long exchange rates, we find that the relative price plays an important role for PPP reversion when real shocks occur. Third, protracted hump-shaped responses of real exchange rates are frequently observed when there is a relative price shock, leading to sluggish adjustments toward PPP. Nominal exchange rate shocks generate humped dynamics much less frequently.
\end{abstract}

Keywords: Purchasing Power Parity; Convergence Rate; Half-Life; Up-Life; Quarter-Life; HumpShaped Response; Variance Decomposition

JEL Classification: C32; F31

*I thank Masao Ogaki, Young-Kyu Moh, Henry Thompson, two anonymous referees, and the editor for helpful comments and Brad Higginbotham for research assistance.

${ }^{\dagger}$ Department of Economics, Auburn University, 0339 Haley Center, Auburn, AL 36849. Tel: (334) 844-2928. Fax: (334) 844-4615. Email: gmmkim@gmail.com. 


\section{Introduction}

In the tradition of Dornbusch (1976), conventional rational expectations sticky price models implicitly assume the same convergence rates for the nominal exchange rate and the relative price. In such models, real exchange rate deviations can be persistent as nominal prices adjust at a slow rate. However, as pointed out by Rogoff (1996), observed persistence of real exchange rate deviations is too high to be explained by such nominal rigidities. Chari et al. (2002) also show an array of sticky price models fails to generate persistence of real exchange rates.

Engel and Morley (2001) propose a state-space model that allows the nominal exchange rate and the relative price to adjust at different speeds. A similar attempt was made by Cheung et al. (2004) who use a vector error correction model (VECM) of the nominal exchange rate and the relative price. Using the current float monthly data for five developed countries, they find that the reversion rate toward Purchasing Power Parity (PPP) is primarily driven by nominal exchange rate adjustment rather than relative price adjustment, which is at odds with the conventional view that addresses a dominant role of nominal prices (see, for example, Stockman, 1987; Rogoff, 1996; Obstfeld and Rogoff, 2000).

However, it is not clear if the relative price (price ratio) adjustment is directly linked to such nominal rigidities, because the relative price changes when economic fundamentals change disproportionately across countries. For instance, country-specific productivity shocks may result in changes in the relative price, and real exchange rates may inherit persistence of real shocks.

This point is closely related to Steinsson's (2008) recent study. He shows that real shocks such as productivity shocks tend to generate hump-shaped dynamics of the real exchange rate, which contributes to generate half-lives that match to observed persistence of the US real exchange rate, while monetary shocks fail to do that. ${ }^{1}$ Our empirical findings are roughly consistent with this claim.

Major contributions of this paper are the following. First, we point out there are cases where VECMs are of limited usefulness in regards with measuring persistence, even when all the variables in the system are not weakly exogenous. For example, VECMs provide the same half-life as that of the univariate method when the chosen number of lags is one.

\footnotetext{
${ }^{1}$ Complete description of his underlying model is available at http://www.columbia.edu/ js3204.
} 
Second, Using Taylor's (2002) century-long exchange rate data for 11 developed countries with the US dollar as a base currency, we find an important role of relative price adjustment in real exchange rate dynamics when real shocks occur. We also find that relative prices often converge at a slower rate than nominal exchange rates when relative price shocks occur. ${ }^{2}$

Third, we observed protracted responses of the real exchange rate more often when real shocks occur. Such hump-shaped responses are observed a lot less frequently when there is a nominal exchange rate shock. These findings are consistent with Steinsson's (2008) results from his underlying microfounded sticky price model. We also implement variance decomposition analysis. For majority countries, we find that nominal exchange rates hardly explain variations of relative prices, while relative prices explain a great deal of variations of nominal exchange rates in the long-run, which implies that the relative price serves as an attractor for the nominal exchange rate.

The present paper is organized as follows. In Section 2, we outline our baseline VECM and demonstrate that VECMs may be of limited usefulness under a certain circumstances. It will also provide some pretest results. Section 3 reports estimates for relative contributions of the nominal exchange rate and the relative price in PPP reversion. In section 4, we report the estimates for an array of metrics including the half-life, up-life, and quarter-life along with some test statistics for the hump-shaped dynamics. The variance decomposition estimates are also reported. Section 5 concludes.

\section{The Econometric Model and Pretest Results}

\subsection{The Model}

Let $e_{t}$ be the log nominal exchange rate as the unit price of the foreign currency in terms of the domestic currency. $\tilde{p}_{t}$ is the $\log$ relative price, $p_{t}-p_{t}^{*}$, where $p_{t}$ and $p_{t}^{*}$ are the log domestic price and the log foreign price, respectively. The log real exchange rate $\left(s_{t}\right)$ is $e_{t}-\tilde{p}_{t}$.

When $e_{t}$ and $\tilde{p}_{t}$ are individually $I(1)$, but cointegrated with the cointegrating vector $[1-1]$, the

\footnotetext{
${ }^{2}$ Cheung et al. (2004) report convergence rates only when there is a nominal exchange rate shock (p.145). That is, they find faster convergence rate for the relative price than the nominal exchange rate in response to nominal shocks. Our findings also confirm such results. However, we find quite different results when there is a relative price shock.
} 
Granger Representation Theorem (Engle and Granger, 1987) implies the following VECM of $e_{t}$ and $\tilde{p}_{t}$.

$$
\left[\begin{array}{c}
\Delta e_{t} \\
\Delta \tilde{p}_{t}
\end{array}\right]=\mathbf{a}+\left[\begin{array}{c}
\rho_{1} \\
\rho_{2}
\end{array}\right] s_{t-1}+\sum_{j=1}^{k}\left[\begin{array}{cc}
\beta_{11, j} & \beta_{12, j} \\
\beta_{21, j} & \beta_{22, j}
\end{array}\right]\left[\begin{array}{c}
\Delta e_{t-j} \\
\Delta \tilde{p}_{t-j}
\end{array}\right]+\mathbf{C}\left[\begin{array}{c}
u_{t}^{e} \\
u_{t}^{\tilde{p}}
\end{array}\right],
$$

where $\mathbf{a}$ is a $2 \times 1$ vector of constants, $s_{t-1}$ denotes the error correction term, and $\rho$ 's are the convergence rates of $e_{t}$ and $\tilde{p}_{t}$. $\mathbf{C}$ is a $2 \times 2$ matrix that describes contemporaneous relations between structural shocks $u_{t}^{e}$ and $u_{t}^{\tilde{p}}$. Equivalently,

$$
\Delta \mathbf{y}_{t}=\mathbf{a}+\rho \beta^{\prime} \mathbf{y}_{t-1}+\sum_{j=1}^{k} \mathbf{B}_{j} \Delta \mathbf{y}_{t-j}+\mathbf{C} \mathbf{u}_{t}
$$

where $\beta=\left[\begin{array}{ll}1 & -1\end{array}\right]^{\prime}$ is the the known cointegrating vector and $\mathbf{y}_{t}=\left[\begin{array}{ll}e_{t} & \tilde{p}_{t}\end{array}\right]^{\prime}$.

It should be noted that the system (1) allows different convergence rates for $e_{t}$ and $\tilde{p}_{t}$ toward PPP, while the conventional univariate equation approach of real exchange rates implicitly assumes the same convergence rate for $e_{t}$ and $\tilde{p}_{t}\left(\rho_{1}=\rho_{2}=\rho\right)$. That is, the conventional single equation approach typically employs the following regression equation.

$$
\Delta s_{t}=a+\rho s_{t-1}+\sum_{j=1}^{k} \beta_{j} \Delta s_{t-j}+u_{t}
$$

where $u_{t}$ denotes a real exchange rate shock that is a composite shock of $u_{t}^{e}$ and $u_{t}^{\tilde{p}}$ in $(1)$.

However, it is well-known that the benefit from such generalization is limited when either $e_{t}$ or $\tilde{p}_{t}$ is weakly exogenous $\left(\rho_{1}=0\right.$ or $\left.\rho_{2}=0\right)$. We show that even when $\rho_{1} \neq 0$ and $\rho_{2} \neq 0$, there is no gain of using the VECM (with respect to measuring speeds of reversion separately) over the univariate equation for the cases described below.

Remark: When $k=0$, nominal exchange rate shocks and relative price shocks generate identical persistence of the real exchange rate. 
Assuming $k=0$, rewrite (1) as follows.

$$
\begin{aligned}
& \Delta e_{t}=a_{1}+\rho_{1} s_{t-1}+c_{11} u_{t}^{e}+c_{12} u_{t}^{\tilde{p}} \\
& \Delta \tilde{p}_{t}=a_{2}+\rho_{2} s_{t-1}+c_{21} u_{t}^{e}+c_{22} u_{t}^{\tilde{p}},
\end{aligned}
$$

where $a_{i}$ is the $i^{\text {th }}$ element of $\mathbf{a}$ and $c_{i j}$ denotes the $(i, j)^{\text {th }}$ element of $\mathbf{C}$. Subtracting the second equation from the first one, we get the following.

$$
\Delta e_{t}-\Delta \tilde{p}_{t}=\left(a_{1}-a_{2}\right)+\left(\rho_{1}-\rho_{2}\right) s_{t-1}+\left(c_{11}-c_{21}\right) u_{t}^{e}+\left(c_{12}-c_{22}\right) u_{t}^{\tilde{p}}
$$

Let $\Delta s_{t}=\Delta e_{t}-\Delta \tilde{p}_{t}, a=a_{1}-a_{2}, \rho=\rho_{1}-\rho_{2}$, and $u_{t}=\left(c_{11}-c_{21}\right) u_{t}^{e}+\left(c_{12}-c_{22}\right) u_{t}^{\tilde{p}}$, then (4) reduces to $(3) .^{3,4}$

\section{$2.2 \quad$ Pretest Results}

In this section, we test the cointegrating relation between $e_{t}$ and $\tilde{p}_{t}$. When the cointegrating vector is known, the most straightforward way to verify the PPP hypothesis is to perform unit root tests on the real exchange rate $s_{t}$ (Froot and Rogoff, 1995).

We first implement unit root tests for the current float monthly CPI-based real exchange rates $\left(s_{t}\right)$ with the US dollar as the base currency. ${ }^{5}$ The Augmented Dickey-Fuller (ADF) test does not reject the null of nonstationarity for any country. More powerful DF-GLS test (Elliott et al., 1996) rejects the null only for 5 out of 17 countries, France, Germany, Italy, the Netherlands, and Norway. Further, lag selection criteria for each test often choose one lag, which implies that univariate models may be good enough for the purpose of measuring convergence speeds as is shown in previous section. ${ }^{6}$

Next, we test the unit root hypothesis with the long-horizon annual data for nominal exchange rates

\footnotetext{
${ }^{3}$ This doesn't mean that the half-life estimates from (1) and (3) would be quantitatively identical, because the $\rho$ estimate can be different from the $\rho_{1}-\rho_{2}$ estimate in finite sample.

${ }^{4}$ While it is empirically less important, it can be shown that each shock delivers identical dynamics of real exchange rates even when $k \geq 1$, if $\beta_{11, j}+\beta_{22, j}=\beta_{12, j}+\beta_{21, j}, \forall j=1, \cdots, k$.

${ }^{5}$ We obtain the data from the IFS CD-ROM. Observations are monthly and span from March 1973 to December 1998. All results are available upon requests.

${ }^{6}$ Lopez et al. (2005) show that lag selection procedures are potentially very important in the unit root test literature. Following the recommendation of Ng and Perron (2001), we implement the ADF test with the General-to-Specific (GTS; Hall, 1994) rule and the DF-GLS test with the modified Akaike Information Criteria (MAIC; Ng and Perron, 2001).
} 
and CPIs. We use Taylor's (2002) over 100-year long data for the 15 developed countries. ${ }^{7}$ The sample $^{2}$ period is from 1880 to 1998 for all countries. We report the results in Table 1.

The ADF test rejects the unit root null for 10 out of 15 countries. With the DF-GLS test, we are able to reject the null for one additional country, Australia. Further, all chosen $k$ 's are greater than zero, which implies that the VECM may be more useful than the univariate method regarding estimations of real exchange rate persistence. ${ }^{8}$ In what follows, we focus on these 11 countries for our anlaysis.

Table 1 about here

\section{The Roles of Relative Price and Nominal Exchange Rate Adjust- ments}

In this section, we evaluate the relative contributions of relative price and nominal exchange rate adjustments toward PPP reversion. For this purpose, we consider two types of structural shocks, a positive nominal exchange rate shock $\left(u_{t}^{e}\right)$ and a negative relative price shock $\left(u_{t}^{\tilde{p}}\right)$, that result in a positive shock to real exchange rate. Using conventional impulse-response analysis, we decompose the dynamic reversion path of the real exchange rate towards its long-run equilibrium into the relative price and nominal exchange rate adjustments.

We rewrite $(2)$ as in the following level $\operatorname{VAR}(k+1)$ form.

$$
\mathbf{y}_{t}=\mathbf{a}+\sum_{j=1}^{k+1} \boldsymbol{\Gamma}_{j} \mathbf{y}_{t-j}+\mathbf{C u}_{t}
$$

\footnotetext{
${ }^{7}$ We extended the original data set through 1998, and omitted Portugal, because its price is the GDP deflator. Small number of missing data were filled by usual linear interpolation. Its electronically compiled data set can be downloaded at Michael Bordo's website (http://michael.bordo.googlepages.com/home3).

${ }^{8}$ We also estimated the univariate error correction model (3), which provided similar half-life estimates as those from our VECM. We note that slightly longer half-life estimates were obtained than the three- to five-year consensus half-life (Rogoff, 1996). This is not unusual, though, because longer half-life estimates are often reported when lower frequency data is used. This may be due to the time aggregation bias as Taylor (2001) points out. All results are available upon requests.
} 
where

$$
\begin{aligned}
\boldsymbol{\Gamma}_{1} & =\mathbf{I}_{2}+\rho \beta^{\prime}+\mathbf{B}_{1} \\
\boldsymbol{\Gamma}_{j} & =\mathbf{B}_{j+1}-\mathbf{B}_{j}, j=2, \cdots, k \\
\boldsymbol{\Gamma}_{k+1} & =-\mathbf{B}_{k}
\end{aligned}
$$

Then, under some regularity conditions, the following recursive relations hold (Pesaran and Shin 1996),

$$
\begin{aligned}
& \mathbf{D}_{n}=\boldsymbol{\Gamma}_{1} \mathbf{D}_{n-1}+\boldsymbol{\Gamma}_{2} \mathbf{D}_{n-2}+\cdots+\boldsymbol{\Gamma}_{k+1} \mathbf{D}_{n-k-1}, \quad n=1,2, \cdots \\
& \mathbf{D}_{0}=\mathbf{I}_{2} \text { and } \mathbf{D}_{n}=0 \text { for } n<0,
\end{aligned}
$$

where

$$
\mathbf{D}_{n}=\sum_{j=0}^{n} \mathbf{A}_{j}, \quad \boldsymbol{\Delta} \mathbf{y}_{t}=\sum_{i=0}^{\infty} \mathbf{A}_{i} \mathbf{C u}_{t-i}
$$

which measures the (cumulative) effects of $\mathbf{u}_{t}$ on the levels of $\mathbf{y}_{t+n}$.

Assuming that $\mathbf{C}$ is an upper-triangular matrix obtained by the Cholesky decomposition of the variance-covariance matrix, the impulse-response functions are given as follows.

$$
\begin{aligned}
& \phi_{e}^{\tilde{p}}(n)=\mathbf{e}_{1}^{\prime} \mathbf{D}_{n} \mathbf{C} \mathbf{e}_{2}, \phi_{\tilde{p}}^{\tilde{p}}(n)=\mathbf{e}_{2}^{\prime} \mathbf{D}_{n} \mathbf{C} \mathbf{e}_{2}, \phi_{s}^{\tilde{p}}(n)=\beta^{\prime} \mathbf{D}_{n} \mathbf{C} \mathbf{e}_{2} \\
& \phi_{e}^{e}(n)=\mathbf{e}_{1}^{\prime} \mathbf{D}_{n} \mathbf{C} \mathbf{e}_{1}, \phi_{\tilde{p}}^{e}(n)=\mathbf{e}_{2}^{\prime} \mathbf{D}_{n} \mathbf{C} \mathbf{e}_{1}, \phi_{s}^{e}(n)=\beta^{\prime} \mathbf{D}_{n} \mathbf{C} \mathbf{e}_{1},
\end{aligned}
$$

where $\phi_{i}^{j}(n)$ denotes the response of variable $i$ at time $t+n$ when a unit shock to variable $j$ occurs at time $t$. $\mathbf{e}_{1}$ and $\mathbf{e}_{2}$ are $2 \times 1$ selection vectors. This assumption is consistent with the generalized impulseresponse function (GIRF; Pesaran and Shin, 1998) to $u_{t}^{e}$, which Cheung et al. (2004) use, so that we can compare our results with theirs. Kim (2009) points out that the GIRF yields a set of response functions that are based on extreme identifying assumptions that contradict each other. We use the conventional orthogonalized impulse-response analysis to make all inferences under consistent assumptions.

Finally, we measure the relative contributions of relative price and nominal exchange rate adjustments 
at time $t+n$ when a shock occurs to relative prices at time $t$ as follows. ${ }^{9}$

$$
d_{e}^{\tilde{p}}(n)=\frac{\left|\Delta \phi_{e}^{\tilde{p}}(n)\right|}{\left|\Delta \phi_{e}^{\tilde{p}}(n)\right|+\left|\Delta \phi_{\tilde{p}}^{\tilde{\tilde{p}}}(n)\right|}, d_{\tilde{p}}^{\tilde{p}}(n)=1-d_{e}^{\tilde{p}}
$$

The relative contributions of the variables when there is a nominal exchange rate shock can be similarly obtained.

In Table 2, we report relative contribution estimates as well as their standard errors for $n=1,3,5$, and $10 .{ }^{10}$ Unlike the results by Cheung et al. (2004) with short-horizon monthly data, our results with the long-horizon data imply a significantly important role of relative price adjustment when either shocks occur. For Germany, roughly $40-50 \%$ of the PPP reversion dynamics occur through nominal exchange rate adjustment when there is a nominal shock. In response to relative price shocks, approximately $10-50 \%$ of the reversion was carried out through nominal exchange rate adjustment. For the UK pound, the nominal exchange rate tends to play an important role in the short-run irrespective of the source of shocks. However, relative price adjustment becomes more important in the long-run. Overall, we do not see any dominant role of nominal exchange rate adjustment toward PPP.

\section{Table 2 about here}

We also report estimated impulse-response functions in Figures 1 and 2 to help understand the results in Table 2. We note that our response functions exhibit substantial roles for the relative price compared with those reported by Cheung et al. (2004) using the current float data. We find that no variable plays a dominant role in the PPP reversion toward its long-run equilibrium value whichever shock occurs. It should be also noted that response functions often exhibit hump-shaped dynamics especially when there is a relative price shocks. We revisit this issue in the following section.

\footnotetext{
${ }^{9}$ Cheung et al. (2004) use a slightly different method. For example, they measure the relative contribution of the nominal exchange rate when a relative shock occurs by $d_{e}^{\tilde{p}}(n)=\Delta \phi_{e}^{\tilde{p}}(n) /\left[\Delta \phi_{e}^{\tilde{p}}(n)-\Delta \phi_{\tilde{p}}^{\tilde{p}}(n)\right]$. This has no problem unless $\Delta \phi_{e}^{\tilde{p}}(n)$ and $\Delta \phi_{\tilde{p}}^{\tilde{p}}(n)$ have the same sign. When they share the same sign, say, both negative, $d_{e}^{\tilde{p}}(n)$ is not bounded by 1 even though $d_{e}^{\tilde{p}}(n)+d_{\tilde{p}}^{\tilde{p}}(n)=1$ by construction. Our method does not have such problems and when $\Delta \phi_{e}^{\tilde{p}}(n)$ and $\Delta \phi_{\tilde{p}}^{\tilde{p}}(n)$ have different signs, our measure coincides with their measure.

${ }^{10}$ Standard errors were obtained by 10,000 nonparametric residual-based bootstrap simulations at the point estimate for each country.
} 
Figures 1 and 2 about here

\section{Speed of Adjustments and Hump-Shaped Responses}

We report our point estimates for the persistence parameters in (1) along with 95\% nonparametric confidence intervals in Table 3. Corresponding half-life estimates and associated $95 \%$ confidence intervals are reported in Table 4. Overall, we obtain quite strong evidence of nominal exchange rate and relative price adjustments toward PPP. All $\rho_{1}$ and $\rho_{2}$ estimates exhibit correct signs with an exception of Italy when there is a relative price shock.

Cheung et al. (2004) report a surprising empirical finding with regard to the adjustment speeds of the nominal exchange rate and the relative price when a nominal exchange rate shock occurs. They report faster convergence rates for the relative price than that of the nominal exchange rate, which seems to be at odds with the conventional sticky price model. Putting it differently, their results imply that the sluggish reversion rate of real exchange rates are mainly due to slow adjustments of the nominal exchange rate. Engel and Morley (2001) provide similar evidence and argue that the real puzzle is why nominal exchange rate converges so slowly.

We note that Cheung et al. (2004) report half-life estimates only when there is a nominal exchange rate shock. They did that because they find that the nominal exchange rate plays a dominant role for real exchange rate dynamics when the current float data is used. As can be seen in Table 2, we find no dominant role of the nominal exchange rate when we use Taylor's (2002) century-long data. So we report half-life estimates for both cases.

With nominal exchange rate shocks, we find fairly similar results as those reported by Cheung et al. (2004). That is, we find slower adjustment rates of the nominal exchange rate than the relative price for 10 out of 11 countries. However, the magnitude of changes in relative price toward the long-run equilibrium was much larger than that of Cheung et al. (2004) with the current float monthly frequency data.

When there is a (negative) relative price shock, we find more sluggish convergence rates for relative prices than nominal exchange rates for 6 out of 11 countries. It should be noted that hump-shaped 
responses are often observed for both the nominal exchange rate and the relative price when relative price shocks occur. Such responses are known to result in delayed overshooting (Eichenbaum and Evans, 1995) or persistent deviations of the real exchange rate (Steinsson, 2008). We also find it challenging to measure half-lives of the nominal exchange rate and the relative price by a conventional method. Especially, the half-life metric may be quite misleading when the response function exhibits humped dynamics, because it is not clear when the deviation adjusts half-way to its long-run equilibrium. For example, the half-life of the relative price adjustment would be quite different if we measure the half-life since the peak of its response after 3 years (see Figure 1.e) instead of the initial size of the deviation as is conventionally done.

Tables 3 and 4 about here

We note that relative price shocks tend to result in longer deviations of real exchange rates than nominal exchange rate shocks. For example, the half-life estimate is longer for 8 out of 11 countries in response to the relative price shock than to the nominal exchange rate shock. Steinsson (2008), in a fully microfounded model, explains that such prolonged responses are mainly due to hump-shaped dynamics in response to an array of real shocks such as productivity shocks, government spending shocks, and cost-push shocks, while monetary shocks fail to generate humped dynamics of the real exchange rate. His modified sticky price model is able to match observed persistence of the real exchange rate when there's a real shock, which motivates us to investigate the existence of hump-shaped responses in our VECM.

In addition to the half-life (HL), the conventional measure of persistence, Steinsson (2008) proposes two measures of hump-shaped responses, the up-life (UL) and the quarter-life (QL). UL denotes the largest $n$ such that $\phi(n-1) \geq 1$ and $\phi(n)<1$, where $\phi(j)$ is the $j$-period ahead response function. Likewise, QL denotes the largest $n$ such that $\phi(n-1) \geq 0.25$ and $\phi(n)<0.25$. When $\mathrm{UL}=0$, there's no hump-shaped dynamics. Another interesting measure is the ratio of UL and HL, which is bounded by 0 and 1 . When UL/HL is close to 1 , the real exchange rate stays longer above the initial response before it falls below that. The other measure is about the monotonicity of convergence. If deviations die out at a constant rate without humped dynamics, HL should equal to QL minus HL. In other words, $2 \mathrm{H}$ - QL can be viewed as a measure of the degree of hump-shaped responses. 
We report estimates for UL and QL in Table 5. Then, we construct these two measures of humpshaped responses with some statistical inferences via 10,000 nonparametric bootstrap simulations (see Table 6).

We first note, for 9 out of 11 countries, UL is shorter for the nominal exchange rate shock than for the relative price shock. Further, QL estimates are longer for the relative price shock for 8 out of 11 countries. These results strongly support finding of Steinsson (2008) when we interpret the nominal exchange rate shock and the relative price shock as the monetary and the real shock, respectively, as in most conventional open macroeconomics models.

In addition to the point estimates for UL/HL and $2 \mathrm{HL}-\mathrm{QL}$, we provide two frequency statistics for $\mathrm{UL} / \mathrm{HL}=0\left(\mathrm{pc}_{u}\right)$ and $2 \mathrm{HL}-\mathrm{QL}<0\left(\mathrm{pc}_{q}\right)$, which is consistent with no hump-shaped response. ${ }^{11}$ Note that $\mathrm{pc}_{u}$ and $\mathrm{pc}_{q}$ are less with the relative shock for 8 and 7 out of 11 countries, respectively, which is again consistent with Steinsson's (2008) results.

Tables 5 and 6 about here

Lastly, we also implement the variance decomposition analysis, and report the results in Table 7. As before, we obtain the standard errors from 10,000 nonparametric residual-based bootstrap simulations. One of the most notable findings is that the nominal exchange rate plays virtually no role in explaining relative price variations, while relative prices serve as an attractor for nominal exchange rates for many countries especially in the intermediate- to long-term with exceptions of Australia, Germany, and the Netherlands. For the UK, for instance, the nominal exchange rate explains less than $5 \%$ of the relative price forecast variations, while the relative price explains about $78 \%$ and $65 \%$ of the nominal exchange rate variations in 5 and 10 years, respectively. These findings again corroborate a non-negligible role of the relative price in real exchange rate dynamics.

\section{Insert Table 7}

\footnotetext{
${ }^{11}$ For example, $\mathrm{pc}_{u}$ denotes the number of no hump-shaped responses out of 10,000 bootstrap simulations.
} 


\section{Conclusion}

This paper investigates the relative contributions of nominal exchange rate and relative price adjustments toward PPP in a VECM framework. Using over hundred-year long data for 11 currencies against the US dollar, we find that relative price adjustments play an important role in real exchange rate dynamics, especially when real shocks occur.

Our results sharply contrast with those of Cheung et al. (2004) who reported a dominant role of nominal exchange rate adjustment with the current float data for 5 real exchange rates. We confirm their results for nominal exchange rate shocks but not for relative price shocks.

One of the striking results of Cheung et al. (2004) was the finding of much slower convergence rates of nominal exchange rates than those of relative prices, which corroborate the findings of Engel and Morley (2001) who also use the current float quarterly data for G7 countries. We again confirm their results when there are nominal exchange rate shocks. However, we fail to find similar results for relative price shocks because we often find opposite observations for many countries.

We also note hump-shaped dynamics of the real exchange rate occur quite often when there is a relative price shock, leading to prolonged deviations of the real exchange rate. Hump-shaped responses are far less frequently observed when nominal exchange rate shocks occur. Our statistical tests are overall consistent with Steinsson's (2008) fully microfounded open macroeconomics sticky price model.

Our variance decomposition analysis provides additional evidence in support of relative prices as being pivotal in real exchange rate dynamics. For majority countries, we find that relative prices explain a great deal of nominal exchange rate variations in the intermediate- to long-term, while nominal exchange rates hardly explain real exchange rate variations. 


\section{Reference}

1. Chari, V.V., Patrick J. Kehoe, and Ellen R. McGrattan (2002), "Can sticky price models generate volatile and persistent real exchange rates?" Review of Economic Studies 69, 533-563.

2. Cheung, Yin-Wong, Kon S. Lai, and Michael Bergman (2004), "Dissecting the ppp puzzle: The unconventional roles of nominal exchange rate and price adjustments," Journal of International Economics 64, 135-150.

3. Dornbusch, Rudiger (1976), "Expectations and exchange rate dynamics," Journal of Political Economy 84, 1161-1176.

4. Eichenbaum, Martin and Charles L. Evans (1995), "Some empirical evidence on the effects of shocks to monetary policy on exchange rates," Quarterly Journal of Economics 110, 975-1009.

5. Elliott, Graham, Thomas Rothenberg, and James H. Stock (1996), "Efficient tests for an autoregressive unit root," Econometrica 64, 813-836.

6. Engel, Charles and James C. Morley (2001), "The adjustment of prices and the adjustment of the exchange rate," NBER Working Paper No. 8550.

7. Engle, Robert F. and C. W. J. Granger (1987), "Co-integration and error correction: representation, estimation, and testing," Econometrica 55, 251-276.

8. Froot, Kenneth A. and Kenneth Rogoff (1995), "Perspectives on PPP and long-run real exchange rates," in Gene M. Grossman and Kenneth Rogoff, editors, Handbook of International Economics, Vol. III, 1647-1688, North-Holland, Amsterdam

9. Hall, Alastair (1994), "Testing for a unit root in time series with pretest data-based model selection," Journal of Business and Economic Statistics 12, 461-470.

10. Kim, Hyeongwoo (2009), "Generalized impulse response analysis: general or extreme?," $M P R A$ Working Paper No.17014. 
11. Lopez, Claude, Christian Murray, and David H. Papell (2005), "State of the art unit root tests and purchasing power parity," Journal of Money, Credit, and Banking 37, 361-369.

12. Ng, Serena and Pierre Perron (2001), "Lag length selection and the construction of unit root tests with good size and power," Econometrica 69, 1519-1554.

13. Obstfeld, Maurice and Kenneth Rogoff (2000), "The six major puzzles in international macroeconomics: Is there a common cause?" NBER Macroeconomics Annual 15, 339-390.

14. Pesaran, M. Hashem and Yongcheol Shin (1996), "Cointegration and speed of convergence to equilibrium," Journal of Econometrics 71, 117-143.

15. Pesaran, M. Hashem and Yongcheol Shin (1998), "Generalized impulse response analysis in linear multivariate models," Economics Letters 58, 17-29.

16. Rogoff, Kenneth (1996), "The purchasing power parity puzzle," Journal of Economic Literature 34, 647-668.

17. Steinsson, Jón (2008), "The dynamic behavior of the real exchange rate in sticky price models," American Economic Review 98, 519-533.

18. Stockman, Alan C. (1987), "The equilibrium approach to exchange rates," Federal Reserve Bank of Richmond Economic Review.

19. Taylor, Alan M. (2001), "Potential pitfalls for the purchasing-power-parity puzzle? Sampling and specification biases in mean-reversion tests of the law of one price," Econometrica 69, 473-498.

20. Taylor, Alan M. (2002), "A century of purchasing power parity," Review of Economics and Statistics $84,139-150$. 
Table 1. Unit Root Tests: Long-Horizon Annual Data

$\Delta s_{t}=a+\rho s_{t-1}+\sum_{j=1}^{k} \beta_{j} \Delta s_{t-j}+\varepsilon_{t}$

$s_{t}=\beta^{\prime} \mathbf{y}_{t}, \beta=\left[\begin{array}{ll}1 & -1\end{array}\right]^{\prime}, \mathbf{y}_{t}=\left[\begin{array}{ll}e_{t} & \tilde{p}_{t}\end{array}\right]^{\prime}, \tilde{p}_{t}=p_{t}-p_{t}^{*}$

\begin{tabular}{lccccc}
\hline \hline & \multicolumn{2}{c}{ ADF Test } & & \multicolumn{2}{c}{ DF-GLS Test } \\
\cline { 2 - 3 } \cline { 5 - 6 } Country & $k_{\mathrm{GTS}}$ & ADF & & $k_{\mathrm{MAIC}}$ & DF-GLS \\
\hline Australia & 1 & -2.548 & & 0 & $-1.944^{*}$ \\
Belgium & 1 & $-4.168^{* * *}$ & & 3 & $-2.423^{* *}$ \\
Canada & 0 & -1.154 & & 0 & -1.330 \\
Denmark & 6 & -1.251 & & 6 & -1.258 \\
Finland & 1 & $-6.002^{* * *}$ & & 8 & $-2.358^{* *}$ \\
France & 2 & $-2.985^{* *}$ & & 6 & -1.088 \\
Germany & 1 & $-2.944^{* *}$ & & 2 & $-2.011^{* *}$ \\
Italy & 2 & $-4.286^{* * *}$ & & 0 & $-3.366^{* * *}$ \\
Japan & 6 & -0.056 & & 2 & 0.307 \\
Netherlands & 1 & $-2.634^{*}$ & & 2 & $-2.352^{* *}$ \\
Norway & 1 & $-3.495^{* * *}$ & & 5 & $-2.030^{* *}$ \\
Spain & 1 & $-3.244^{* *}$ & & 3 & $-2.101^{* *}$ \\
Sweden & 1 & $-3.724^{* * *}$ & & 2 & $-2.358^{* *}$ \\
Switzerland & 2 & -1.491 & & 2 & -0.758 \\
UK & 4 & $-2.579^{*}$ & & 4 & $-2.178^{* *}$ \\
\hline \hline
\end{tabular}

Note: i) Observations span from 1880 to 1998 with the exceptions of Japan (1885-1998) and Switzerland (1892-1998). ii) For the Augmented Dickey-Fuller tests, the numbers of lags were chosen by the general-to-specific rule (Hall, 1994). iii) For the DF-GLS tests, the modified Akaike Information Criteria (Ng and Perron, 2001) was employed. iv) For the DF-GLS tests, $s_{t}$ denotes the GLS detrended real exchange rates. ${ }^{*}{ }^{*},{ }^{* *}$, and ${ }^{* * *}$ denote significance at the $10 \%, 5 \%$, and $1 \%$ levels, respectively. 
Table 2. Relative Contributions of Nominal Exchange Rate and Relative Price Adjustments to PPP Reversion

\begin{tabular}{|c|c|c|c|c|c|c|c|c|c|c|c|c|c|}
\hline \multirow[b]{2}{*}{ Country } & \multirow[b]{2}{*}{ Shock } & \multicolumn{3}{|c|}{$j=1$} & \multicolumn{3}{|c|}{$j=3$} & \multicolumn{3}{|c|}{$j=5$} & \multicolumn{3}{|c|}{$j=10$} \\
\hline & & $d_{e}$ & $d_{\tilde{p}}$ & s.e. & $d_{e}$ & $d_{\tilde{p}}$ & s.e. & $d_{e}$ & $d_{\tilde{p}}$ & s.e. & $d_{e}$ & $d_{\tilde{p}}$ & s.e. \\
\hline \multirow[t]{2}{*}{ Australia } & $e$ & 0.303 & 0.697 & 0.183 & 0.397 & 0.603 & 0.205 & 0.400 & 0.600 & 0.212 & 0.400 & 0.600 & 0.214 \\
\hline & $\tilde{p}$ & 0.215 & 0.785 & 0.257 & 0.406 & 0.594 & 0.229 & 0.401 & 0.599 & 0.214 & 0.400 & 0.600 & 0.214 \\
\hline \multirow[t]{2}{*}{ Belgium } & $e$ & 0.497 & 0.503 & 0.164 & 0.586 & 0.414 & 0.135 & 0.586 & 0.414 & 0.161 & 0.571 & 0.429 & 0.191 \\
\hline & $\tilde{p}$ & 0.571 & 0.429 & 0.233 & 0.609 & 0.391 & 0.165 & 0.591 & 0.409 & 0.155 & 0.579 & 0.421 & 0.192 \\
\hline \multirow[t]{2}{*}{ Finland } & $e$ & 0.811 & 0.189 & 0.118 & 0.866 & 0.134 & 0.167 & 0.549 & 0.451 & 0.211 & 0.860 & 0.140 & 0.191 \\
\hline & $\tilde{p}$ & 0.869 & 0.131 & 0.088 & 0.876 & 0.124 & 0.100 & 0.487 & 0.513 & 0.221 & 0.777 & 0.223 & 0.170 \\
\hline \multirow[t]{2}{*}{ France } & $e$ & 0.472 & 0.528 & 0.263 & 0.352 & 0.648 & 0.281 & 0.224 & 0.776 & 0.285 & 0.307 & 0.693 & 0.282 \\
\hline & $\tilde{p}$ & 0.639 & 0.361 & 0.125 & 0.527 & 0.473 & 0.193 & 0.478 & 0.522 & 0.237 & 0.059 & 0.941 & 0.276 \\
\hline \multirow[t]{2}{*}{ Germany } & $e$ & 0.510 & 0.490 & 0.208 & 0.388 & 0.612 & 0.191 & 0.461 & 0.539 & 0.186 & 0.483 & 0.517 & 0.204 \\
\hline & $\tilde{p}$ & 0.131 & 0.869 & 0.256 & 0.443 & 0.557 & 0.228 & 0.463 & 0.537 & 0.192 & 0.482 & 0.518 & 0.204 \\
\hline \multirow[t]{2}{*}{ Italy } & $e$ & 0.477 & 0.523 & 0.150 & 0.685 & 0.315 & 0.097 & 0.796 & 0.204 & 0.160 & 0.564 & 0.436 & 0.191 \\
\hline & $\tilde{p}$ & 0.692 & 0.308 & 0.131 & 0.946 & 0.054 & 0.250 & 0.163 & 0.837 & 0.221 & 0.819 & 0.181 & 0.213 \\
\hline \multirow[t]{2}{*}{ Netherlands } & $e$ & 0.045 & 0.955 & 0.192 & 0.657 & 0.343 & 0.175 & 0.696 & 0.304 & 0.178 & 0.694 & 0.306 & 0.181 \\
\hline & $\tilde{p}$ & 0.983 & 0.017 & 0.247 & 0.600 & 0.400 & 0.195 & 0.681 & 0.319 & 0.178 & 0.694 & 0.306 & 0.180 \\
\hline \multirow[t]{2}{*}{ Norway } & $e$ & 0.687 & 0.313 & 0.208 & 0.747 & 0.253 & 0.140 & 0.729 & 0.271 & 0.149 & 0.686 & 0.314 & 0.207 \\
\hline & $\tilde{p}$ & 0.325 & 0.675 & 0.192 & 0.968 & 0.032 & 0.154 & 0.789 & 0.211 & 0.143 & 0.715 & 0.285 & 0.185 \\
\hline \multirow[t]{2}{*}{ Spain } & $e$ & 0.057 & 0.943 & 0.221 & 0.562 & 0.438 & 0.203 & 0.592 & 0.408 & 0.218 & 0.596 & 0.404 & 0.235 \\
\hline & $\tilde{p}$ & 0.725 & 0.275 & 0.163 & 0.809 & 0.191 & 0.183 & 0.658 & 0.342 & 0.224 & 0.598 & 0.402 & 0.233 \\
\hline \multirow[t]{2}{*}{ Sweden } & $e$ & 0.707 & 0.293 & 0.158 & 0.801 & 0.199 & 0.133 & 0.810 & 0.190 & 0.156 & 0.811 & 0.189 & 0.183 \\
\hline & $\tilde{p}$ & 0.480 & 0.520 & 0.203 & 0.958 & 0.042 & 0.107 & 0.850 & 0.150 & 0.133 & 0.815 & 0.185 & 0.183 \\
\hline \multirow[t]{2}{*}{ UK } & $e$ & 0.963 & 0.037 & 0.177 & 0.900 & 0.100 & 0.122 & 0.467 & 0.533 & 0.200 & 0.184 & 0.816 & 0.258 \\
\hline & $\tilde{p}$ & 0.885 & 0.115 & 0.189 & 0.916 & 0.084 & 0.174 & 0.294 & 0.706 & 0.234 & 0.112 & 0.888 & 0.262 \\
\hline
\end{tabular}

Note: i) Observations span from 1880 to 1998 for all countries. ii) The standard errors were obtained from 10,000 residual-based bootstrap simulations. 
Table 3. Vector Error Correction Model Regressions: Error Correction Terms Estimates $\Delta \mathbf{y}_{t}=\mathbf{a}+\rho \beta^{\prime} \mathbf{y}_{t-1}+\sum_{j=1}^{k} \mathbf{B}_{j} \Delta \mathbf{y}_{t-j}+\mathbf{C} \mathbf{u}_{t}$ $\mathbf{y}_{t}=\left[\begin{array}{ll}e_{t} & \tilde{p}_{t}\end{array}\right]^{\prime}, \tilde{p}_{t}=p_{t}-p_{t}^{*}, \rho=\left[\begin{array}{ll}\rho_{1} & \rho_{2}\end{array}\right]^{\prime}, \mathbf{u}_{t}=\left[\begin{array}{ll}u_{t}^{e} & u_{t}^{\tilde{p}}\end{array}\right]^{\prime}, \mathbf{C}$ is an upper-triangular matrix.

\begin{tabular}{|c|c|c|c|c|c|c|c|}
\hline \multirow[b]{2}{*}{ Country } & \multirow[b]{2}{*}{$k$} & \multicolumn{3}{|c|}{ " Nominal Exchange Rate Equation } & \multicolumn{3}{|c|}{ "Relative Price Equation } \\
\hline & & $\rho_{1}$ & s.e. & CI & $\rho_{2}$ & s.e. & CI \\
\hline Australia & 1 & -0.033 & 0.039 & {$[-0.153,0.025]$} & 0.048 & 0.019 & {$[0.021,0.107]$} \\
\hline Belgium & 1 & -0.114 & 0.065 & {$[-0.267,-0.007]$} & 0.075 & 0.016 & {$[0.042,0.116]$} \\
\hline Finland & 1 & -0.396 & 0.055 & {$[-0.538,-0.297]$} & 0.051 & 0.058 & {$[-0.056,0.176]$} \\
\hline France & 2 & -0.090 & 0.056 & {$[-0.276,0.000]$} & 0.060 & 0.041 & {$[-0.034,0.171]$} \\
\hline Germany & 1 & -0.035 & 0.031 & {$[-0.127,0.012]$} & 0.049 & 0.015 & {$[0.025,0.092]$} \\
\hline Italy & 2 & -0.318 & 0.073 & {$[-0.515,-0.200]$} & -0.095 & 0.063 & {$[-0.244,0.053]$} \\
\hline Netherlands & 1 & -0.045 & 0.035 & {$[-0.159,0.002]$} & 0.036 & 0.016 & {$[0.011,0.082]$} \\
\hline Norway & 1 & -0.108 & 0.036 & {$[-0.208,-0.044]$} & 0.026 & 0.019 & {$[-0.006,0.077]$} \\
\hline Spain & 1 & -0.083 & 0.039 & {$[-0.205,-0.027]$} & 0.048 & 0.019 & {$[0.011,0.100]$} \\
\hline Sweden & 1 & -0.145 & 0.043 & {$[-0.274,-0.080]$} & 0.028 & 0.020 & {$[-0.009,0.082]$} \\
\hline UK & 4 & -0.049 & 0.061 & {$[-0.249,0.055]$} & 0.070 & 0.025 & {$[0.028,0.146]$} \\
\hline
\end{tabular}

Note: i) Observations span from 1880 to 1998 for all countries. ii) The numbers of lags ( $k$ ) were chosen by the general-to-specific rule (Hall, 1994). iii) The 95\% confidence intervals were obtained by getting $2.5 \%$ and $97.5 \%$ percentiles from 10,000 residual-based bootstrap simulations (Efron and Tibshirani, 1993). 


\section{Table 4. Vector Error Correction Model Regressions: Half-Life Estimates}

$$
\Delta \mathbf{y}_{t}=\mathbf{a}+\rho \beta^{\prime} \mathbf{y}_{t-1}+\sum_{j=1}^{k} \mathbf{B}_{j} \Delta \mathbf{y}_{t-j}+\mathbf{C} \mathbf{u}_{t}
$$

$\mathbf{y}_{t}=\left[\begin{array}{ll}e_{t} & \tilde{p}_{t}\end{array}\right]^{\prime}, \tilde{p}_{t}=p_{t}-p_{t}^{*}, \rho=\left[\begin{array}{ll}\rho_{1} & \rho_{2}\end{array}\right]^{\prime}, \mathbf{u}_{t}=\left[\begin{array}{ll}u_{t}^{e} & u_{t}^{\tilde{p}}\end{array}\right]^{\prime}, \mathbf{C}$ is an upper-triangular matrix.

\begin{tabular}{|c|c|c|c|c|c|c|c|c|c|c|c|c|}
\hline \multirow[b]{2}{*}{ Country } & \multicolumn{6}{|c|}{ "Nominal Exchange Rate Shock } & \multicolumn{6}{|c|}{ "Relative Price Shock } \\
\hline & $\mathrm{HL}_{\mathrm{s}}$ & CI & $\mathrm{HL}_{\mathrm{e}}$ & CI & $\mathrm{HL}_{\tilde{\mathrm{p}}}$ & CI & $\mathrm{HL}_{\mathrm{s}}$ & CI & $\mathrm{HL}_{\mathrm{e}}$ & CI & $\mathrm{HL}_{\tilde{\mathrm{p}}}$ & CI \\
\hline Australia & 5.431 & {$[2.260,9.510]$} & 7.559 & {$[0.371,17.19]$} & 4.312 & {$[1.303,8.333]$} & 11.22 & {$[4.246,19.64]$} & 9.614 & {$[0.153,23.38]$} & 12.54 & {$[0.067,24.89]$} \\
\hline Belgium & 3.512 & {$[2.282,4.786]$} & 3.972 & {$[2.221,6.458]$} & 2.884 & {$[1.631,4.207]$} & 5.449 & {$[1.119,8.454]$} & 4.337 & {$[0.255,9.182]$} & 8.675 & {$[0.033,10.33]$} \\
\hline Finland & 1.759 & {$[1.175,2.455]$} & 2.108 & {$[1.415,2.812]$} & 0.616 & {$[0.097,5.253]$} & 2.411 & {$[1.556,3.374]$} & 2.079 & {$[1.350,2.787]$} & 0.819 & {$[0.188,2.852]$} \\
\hline France & 4.848 & {$[2.231,8.500]$} & 9.549 & {$[0.079,14.36]$} & 3.660 & {$[0.308,12.69]$} & 1.290 & {$[0.000,7.313]$} & 1.404 & {$[0.534,2.574]$} & 1.492 & {$[0.283,5.308]$} \\
\hline Germany & 7.932 & {$[4.019,12.47]$} & 13.95 & {$[0.041,22.84]$} & 5.343 & {$[2.413,8.619]$} & 9.412 & {$[3.170,15.69]$} & 7.704 & {$[0.237,17.88]$} & 11.68 & {$[0.038,21.34]$} \\
\hline Italy & 4.237 & {$[2.429,5.690]$} & 3.515 & {$[2.059,4.924]$} & 2.713 & {$[0.571,5.933]$} & 2.979 & {$[1.362,5.482]$} & 1.397 & {$[0.233,7.555]$} & 0.556 & {$[0.106,5.174]$} \\
\hline Netherlands & 7.302 & {$[3.104,12.25]$} & 10.49 & {$[3.347,22.61]$} & 3.215 & {$[0.687,7.533]$} & 11.13 & {$[3.853,19.75]$} & 10.75 & {$[0.342,25.55]$} & 12.08 & {$[0.048,23.55]$} \\
\hline Norway & 4.615 & {$[2.785,6.739]$} & 4.813 & {$[2.878,7.217]$} & 4.059 & {$[0.729,9.562]$} & 9.988 & {$[5.919,16.13]$} & 7.307 & {$[4.423,10.98]$} & 0.471 & {$[0.038,11.56]$} \\
\hline Spain & 6.116 & {$[3.233,9.495]$} & 8.199 & {$[0.142,16.69]$} & 4.132 & {$[1.121,7.318]$} & 4.200 & {$[0.959,9.168]$} & 1.966 & {$[0.860,6.931]$} & 0.372 & {$[0.050,17.79]$} \\
\hline Sweden & 3.878 & {$[2.240,5.827]$} & 4.246 & {$[2.320,6.648]$} & 2.715 & {$[0.411,8.664]$} & 6.546 & {$[2.853,10.19]$} & 4.415 & {$[1.810,7.264]$} & 0.553 & {$[0.064,10.39]$} \\
\hline UK & 3.525 & {$[1.794,5.969]$} & 2.180 & {$[0.573,15.74]$} & 6.741 & {$[2.076,11.23]$} & 8.554 & {$[2.868,15.00]$} & 0.759 & {$[0.093,10.14]$} & 12.28 & {$[0.041,21.49]$} \\
\hline
\end{tabular}

Note: i) Observations span from 1880 to 1998 for all countries. ii) The numbers of lags $(k)$ were chosen by the general-to-specific rule (Hall, 1994). iii) Half-Life estimates were obtained from the impulse-response functions. iv) The $95 \%$ confidence intervals for the half-life estimates were also obtained by $2.5 \%$ and $97.5 \%$ percentiles from 10,000 residual-based bootstrap simulations (Efron and Tibshirani, 1993). 
Table 5. Hump-Shaped Dynamics

\begin{tabular}{lcccccccc}
\hline \hline & \multicolumn{3}{c}{ Nominal Exchange Rate Shocks } & \multicolumn{4}{c}{ Relative Price Shocks } \\
Country & UL & s.e. & QL & s.e. & UL & s.e. & QL & s.e. \\
\hline Australia & 0.000 & 0.740 & 10.41 & 4.120 & 6.189 & 3.156 & 16.22 & 6.246 \\
Belgium & 1.284 & 2.110 & 4.963 & 2.150 & 3.650 & 2.686 & 6.829 & 2.852 \\
Finland & 0.000 & 0.265 & 2.445 & 0.475 & 1.151 & 2.118 & 3.069 & 1.881 \\
France & 1.619 & 0.609 & 9.127 & 3.526 & 0.000 & 6.254 & 1.755 & 10.97 \\
Germany & 4.203 & 1.325 & 11.35 & 4.624 & 5.779 & 2.321 & 12.79 & 5.140 \\
Italy & 0.000 & 0.595 & 5.583 & 1.013 & 2.337 & 2.750 & 3.409 & 4.148 \\
Netherlands & 2.374 & 1.137 & 12.37 & 4.837 & 6.073 & 2.578 & 16.20 & 6.535 \\
Norway & 1.919 & 0.829 & 6.750 & 1.944 & 8.086 & 2.247 & 11.64 & 4.245 \\
Spain & 2.797 & 0.915 & 9.133 & 2.830 & 1.239 & 1.615 & 6.981 & 3.388 \\
Sweden & 1.276 & 0.817 & 5.962 & 1.715 & 4.071 & 1.507 & 8.708 & 2.629 \\
UK & 0.000 & 0.504 & 6.478 & 2.760 & 4.735 & 2.637 & 11.74 & 4.940 \\
\hline \hline
\end{tabular}

Note: i) Observations span from 1880 to 1998 for all countries. ii) The numbers of lags ( $k$ ) were chosen by the general-to-specific rule (Hall, 1994). iii) UL and QL denote the up-life and the quarter-life of the real exchange rate (Steinsson, 2008). That is, UL is the largest $n$ such that $\phi(n-1) \geq 1$ and $\phi(n)<1$, where $\phi(j)$ is the j-period ahead response function. Likewise, QL is the largest $n$ such that $\phi(n-1) \geq 0.25$ and $\phi(n)<0.25$. When UL $=0$, there's no hump-shaped dynamics. iv) The standard errors were obtained from 10,000 residual-based bootstrap simulations. 
Table 6. Hump-Shaped Dynamics Tests

\begin{tabular}{|c|c|c|c|c|c|c|c|c|c|c|c|c|}
\hline \multirow[b]{2}{*}{ Country } & \multicolumn{6}{|c|}{ "Nominal Exchange Rate Shocks } & \multicolumn{6}{|c|}{ Relative Price Shocks } \\
\hline & $\mathrm{UL} / \mathrm{HL}$ & s.e. & $\mathrm{pc}_{u}$ & 2HL-QL & s.e. & $\mathrm{pc}_{q}$ & $\mathrm{UL} / \mathrm{HL}$ & s.e. & $\mathrm{pc}_{u}$ & 2HL-QL & s.e. & $\mathrm{pc}_{q}$ \\
\hline Australia & 0.000 & 0.128 & 0.744 & 0.447 & 3.115 & 0.271 & 0.552 & 0.126 & 0.018 & 6.220 & 3.710 & 0.004 \\
\hline Belgium & 0.366 & 0.191 & 0.281 & 2.061 & 2.144 & 0.001 & 0.670 & 0.260 & 0.136 & 4.070 & 2.753 & 0.005 \\
\hline Finland & 0.000 & 0.110 & 0.944 & 1.074 & 0.357 & 0.001 & 0.478 & 0.261 & 0.346 & 1.753 & 2.207 & 0.000 \\
\hline France & 0.334 & 0.146 & 0.080 & 0.569 & 1.592 & 0.293 & 0.000 & 0.300 & 0.741 & 0.826 & 10.90 & 0.220 \\
\hline Germany & 0.530 & 0.100 & 0.003 & 4.519 & 1.414 & 0.000 & 0.614 & 0.160 & 0.031 & 6.036 & 2.272 & 0.008 \\
\hline Italy & 0.000 & 0.121 & 0.934 & 2.891 & 0.888 & 0.007 & 0.784 & 0.313 & 0.141 & 2.550 & 4.727 & 0.134 \\
\hline Netherlands & 0.325 & 0.143 & 0.093 & 2.238 & 1.279 & 0.047 & 0.546 & 0.137 & 0.029 & 6.062 & 2.496 & 0.006 \\
\hline Norway & 0.416 & 0.158 & 0.106 & 2.660 & 0.873 & 0.008 & 0.810 & 0.060 & 0.000 & 8.337 & 2.317 & 0.003 \\
\hline Spain & 0.457 & 0.120 & 0.025 & 3.100 & 0.854 & 0.001 & 0.295 & 0.244 & 0.451 & 1.419 & 1.846 & 0.050 \\
\hline Sweden & 0.329 & 0.198 & 0.370 & 1.794 & 0.694 & 0.014 & 0.622 & 0.157 & 0.036 & 4.385 & 1.373 & 0.002 \\
\hline UK & 0.000 & 0.126 & 0.866 & 0.571 & 2.186 & 0.176 & 0.554 & 0.284 & 0.160 & 5.367 & 3.484 & 0.069 \\
\hline
\end{tabular}

Note: i) Observations span from 1880 to 1998 for all countries. ii) The numbers of lags ( $k$ ) were chosen by the general-to-specific rule (Hall, 1994). iii) UL and QL denote the up-life and the quarter-life of the real exchange rate (Steinsson, 2008). When UL/HL > 0, there's a hump-shape response. When HL > QL - HL, the half-life is larger than the quarter-life, which is consistent with a hump-shape response. iv) The standard errors were obtained from 10,000 residual-based bootstrap simulations. v) $\mathrm{pc}_{u}$ and $\mathrm{pc}_{q}$ denotes ratios of the cases, UL/HL $=0$ and $\mathrm{HL}<\mathrm{QL}-\mathrm{HL}$, out of 10,000 bootstrap sample. That is, when the number is smaller, there is weaker evidence of hump-shape responses. 
Table 7. Variance Decomposition of $j$-Step Ahead Forecast Error

\begin{tabular}{|c|c|c|c|c|c|c|c|c|c|c|c|c|c|}
\hline \multirow[b]{2}{*}{ Country } & \multirow[b]{2}{*}{$x$} & \multicolumn{3}{|c|}{$j=1$} & \multicolumn{3}{|c|}{$j=3$} & \multicolumn{3}{|c|}{$j=5$} & \multicolumn{3}{|c|}{$j=10$} \\
\hline & & $u_{t}^{e}$ & $u_{t}^{\tilde{p}}$ & s.e. & $u_{t}^{e}$ & $u_{t}^{\tilde{p}}$ & s.e. & $u_{t}^{e}$ & $u_{t}^{\tilde{p}}$ & s.e. & $u_{t}^{e}$ & $u_{t}^{\tilde{p}}$ & s.e. \\
\hline \multirow[t]{2}{*}{ Australia } & $e$ & 0.998 & 0.002 & 0.029 & 0.998 & 0.002 & 0.065 & 0.997 & 0.003 & 0.092 & 0.971 & 0.029 & 0.155 \\
\hline & $\tilde{p}$ & 0.005 & 0.995 & 0.004 & 0.020 & 0.980 & 0.016 & 0.041 & 0.959 & 0.032 & 0.106 & 0.894 & 0.082 \\
\hline \multirow[t]{2}{*}{ Belgium } & $e$ & 0.998 & 0.002 & 0.070 & 0.979 & 0.021 & 0.154 & 0.896 & 0.104 & 0.194 & 0.656 & 0.344 & 0.219 \\
\hline & $\tilde{p}$ & 0.002 & 0.998 & 0.002 & 0.018 & 0.982 & 0.012 & 0.049 & 0.951 & 0.031 & 0.126 & 0.874 & 0.082 \\
\hline \multirow[t]{2}{*}{ Finland } & $e$ & 0.898 & 0.102 & 0.069 & 0.483 & 0.517 & 0.109 & 0.249 & 0.751 & 0.081 & 0.116 & 0.884 & 0.063 \\
\hline & $\tilde{p}$ & 0.008 & 0.992 & 0.013 & 0.022 & 0.978 & 0.036 & 0.022 & 0.978 & 0.043 & 0.019 & 0.981 & 0.046 \\
\hline \multirow[t]{2}{*}{ France } & $e$ & 0.794 & 0.206 & 0.090 & 0.553 & 0.447 & 0.167 & 0.452 & 0.548 & 0.195 & 0.376 & 0.624 & 0.235 \\
\hline & $\tilde{p}$ & 0.007 & 0.993 & 0.012 & 0.036 & 0.964 & 0.048 & 0.063 & 0.937 & 0.084 & 0.120 & 0.880 & 0.159 \\
\hline \multirow[t]{2}{*}{ Germany } & $e$ & 0.999 & 0.001 & 0.021 & 0.999 & 0.001 & 0.059 & 0.997 & 0.003 & 0.086 & 0.962 & 0.038 & 0.145 \\
\hline & $\tilde{p}$ & 0.001 & 0.999 & 0.002 & 0.009 & 0.991 & 0.011 & 0.032 & 0.968 & 0.029 & 0.129 & 0.871 & 0.088 \\
\hline \multirow[t]{2}{*}{ Italy } & $e$ & 0.508 & 0.492 & 0.209 & 0.158 & 0.842 & 0.129 & 0.078 & 0.922 & 0.060 & 0.083 & 0.917 & 0.060 \\
\hline & $\tilde{p}$ & 0.000 & 1.000 & 0.008 & 0.015 & 0.985 & 0.024 & 0.038 & 0.962 & 0.041 & 0.067 & 0.933 & 0.062 \\
\hline \multirow[t]{2}{*}{ Netherlands } & $e$ & 0.988 & 0.012 & 0.035 & 0.977 & 0.023 & 0.072 & 0.982 & 0.018 & 0.084 & 0.963 & 0.037 & 0.143 \\
\hline & $\tilde{p}$ & 0.005 & 0.995 & 0.004 & 0.023 & 0.977 & 0.017 & 0.043 & 0.957 & 0.032 & 0.092 & 0.908 & 0.074 \\
\hline \multirow[t]{2}{*}{ Norway } & $e$ & 0.983 & 0.017 & 0.025 & 0.988 & 0.012 & 0.071 & 0.917 & 0.083 & 0.136 & 0.470 & 0.530 & 0.205 \\
\hline & $\tilde{p}$ & 0.000 & 1.000 & 0.001 & 0.002 & 0.998 & 0.007 & 0.005 & 0.995 & 0.017 & 0.017 & 0.983 & 0.046 \\
\hline \multirow[t]{2}{*}{ Spain } & $e$ & 0.944 & 0.056 & 0.055 & 0.840 & 0.160 & 0.132 & 0.746 & 0.254 & 0.171 & 0.583 & 0.417 & 0.203 \\
\hline & $\tilde{p}$ & 0.001 & 0.999 & 0.003 & 0.012 & 0.988 & 0.014 & 0.031 & 0.969 & 0.031 & 0.083 & 0.917 & 0.077 \\
\hline \multirow[t]{2}{*}{ Sweden } & $e$ & 0.993 & 0.007 & 0.033 & 0.915 & 0.085 & 0.118 & 0.726 & 0.274 & 0.172 & 0.358 & 0.642 & 0.162 \\
\hline & $\tilde{p}$ & 0.001 & 0.999 & 0.002 & 0.005 & 0.995 & 0.008 & 0.009 & 0.991 & 0.016 & 0.018 & 0.982 & 0.033 \\
\hline \multirow[t]{2}{*}{$\mathrm{UK}$} & $e$ & 0.931 & 0.069 & 0.088 & 0.951 & 0.049 & 0.114 & 0.783 & 0.217 & 0.176 & 0.648 & 0.352 & 0.227 \\
\hline & $\tilde{p}$ & 0.001 & 0.999 & 0.002 & 0.002 & 0.998 & 0.007 & 0.006 & 0.994 & 0.014 & 0.047 & 0.953 & 0.058 \\
\hline
\end{tabular}

Note: i) Observations span from 1880 to 1998 for all countries. ii) The variance of $j$-step ahead forecast error is $V a r\left(x_{t+j}-E_{t}\left(x_{t+j}\right)\right)$. iii) The standard errors were obtained from 10,000 residual-based bootstrap simulations. 
Figure 1: Responses to a Unit Relative Price Shock

(a) Australi
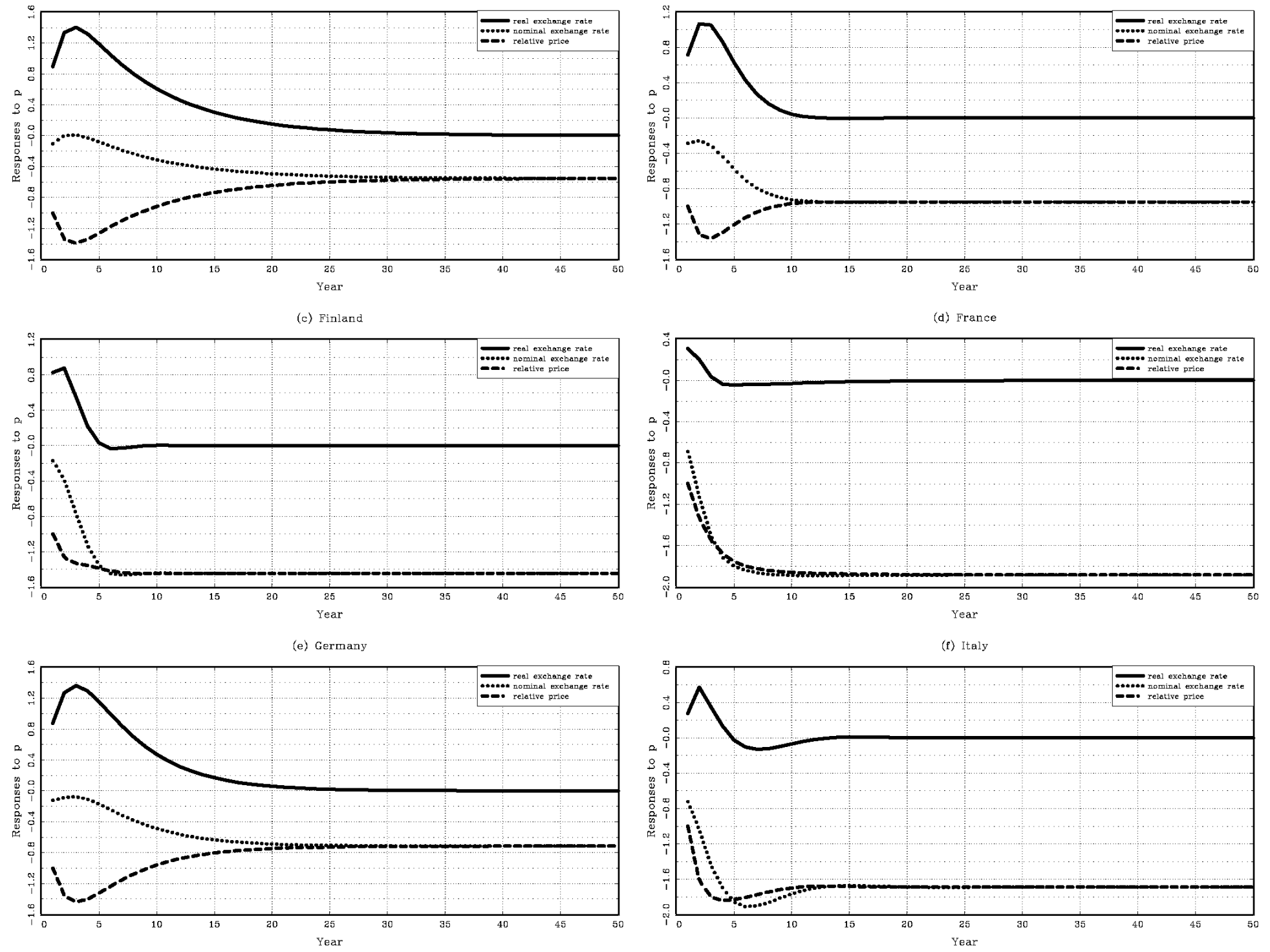
(g) Netherlands

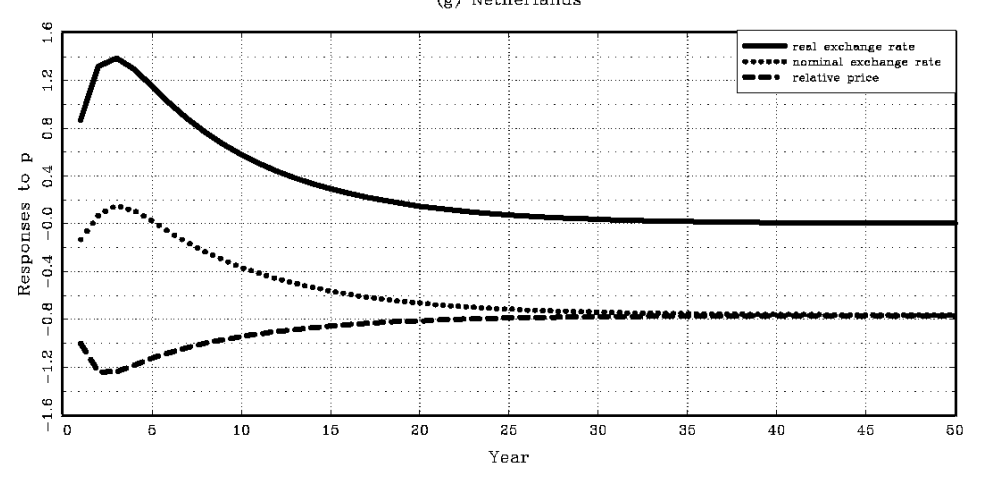

(i) Spain

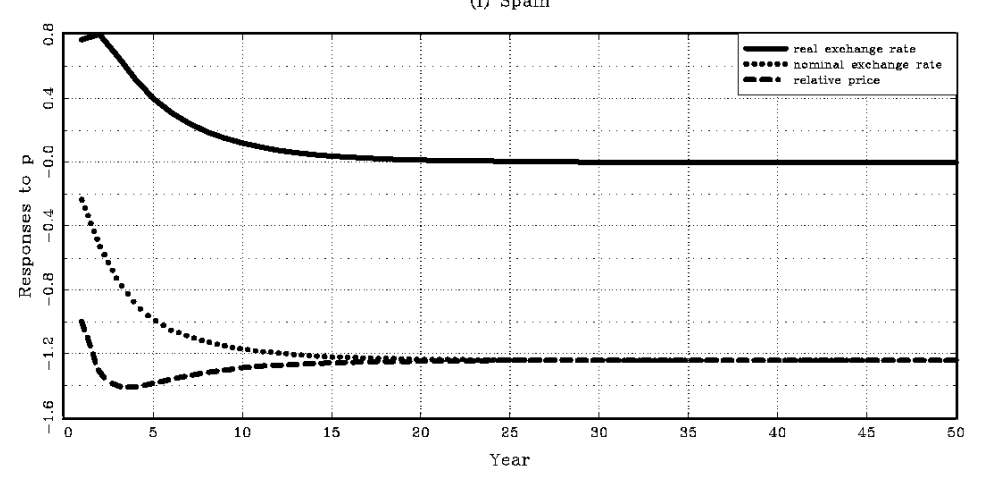

(k) UE

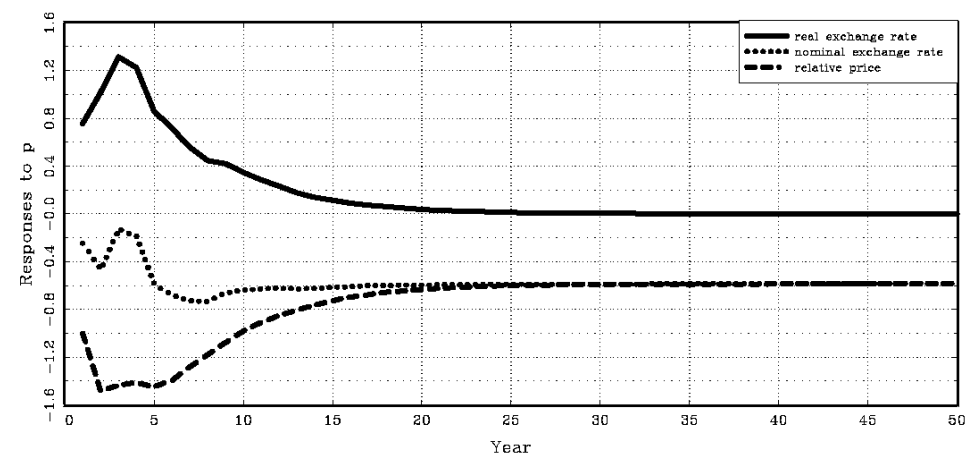

(h) Norway

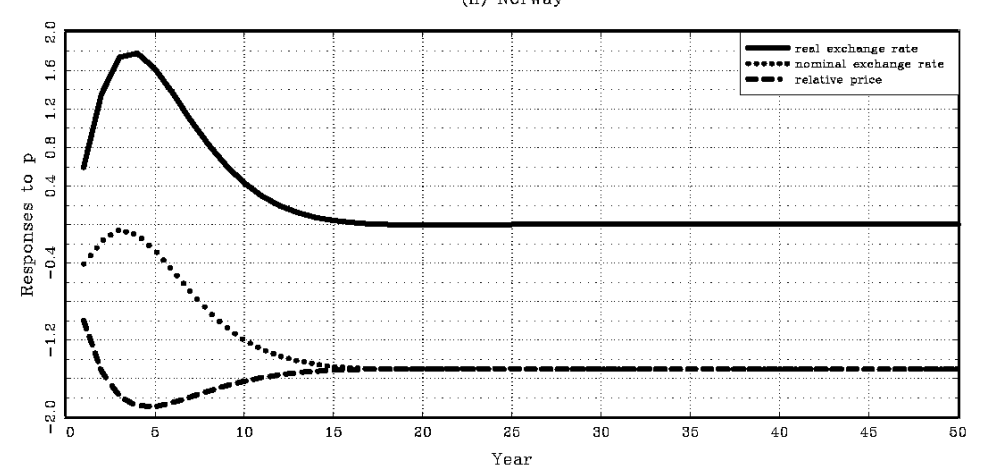

(j) Sweden

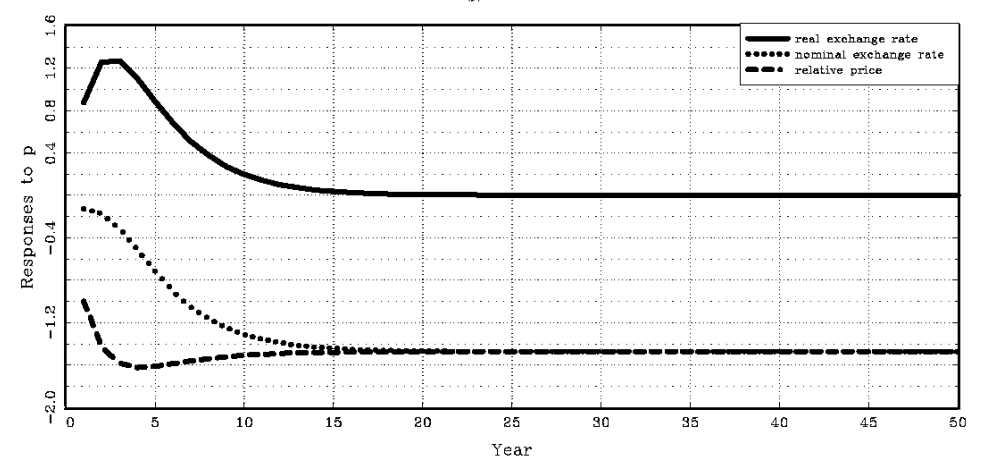


Figure 2: Responses to a Unit Nominal Exchange Rate Shock

(a) Australia

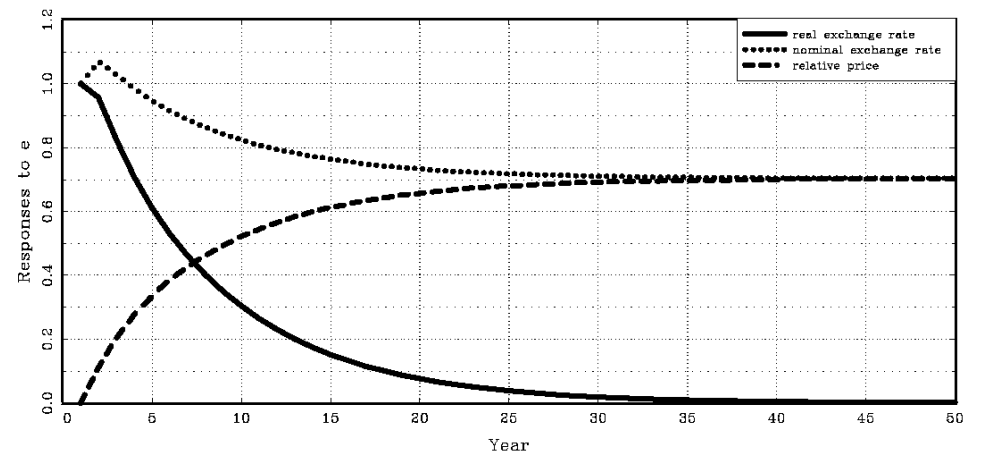

(c) Finland

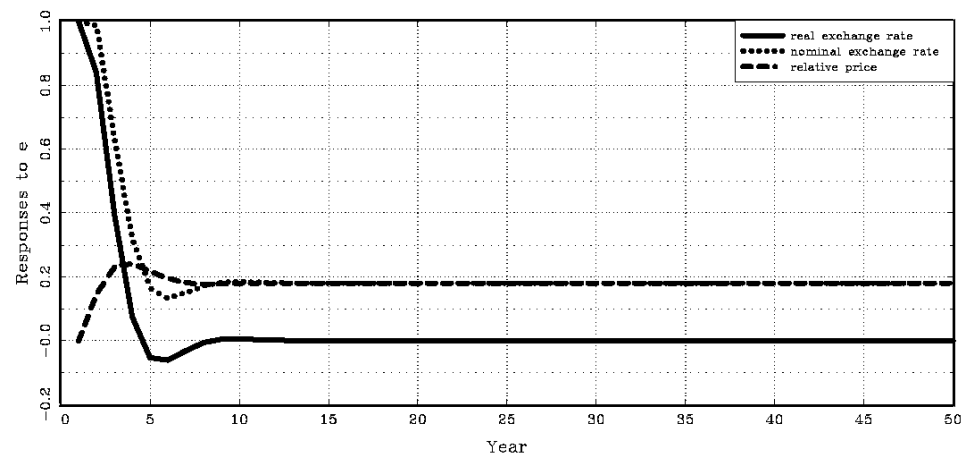

(e) Germany

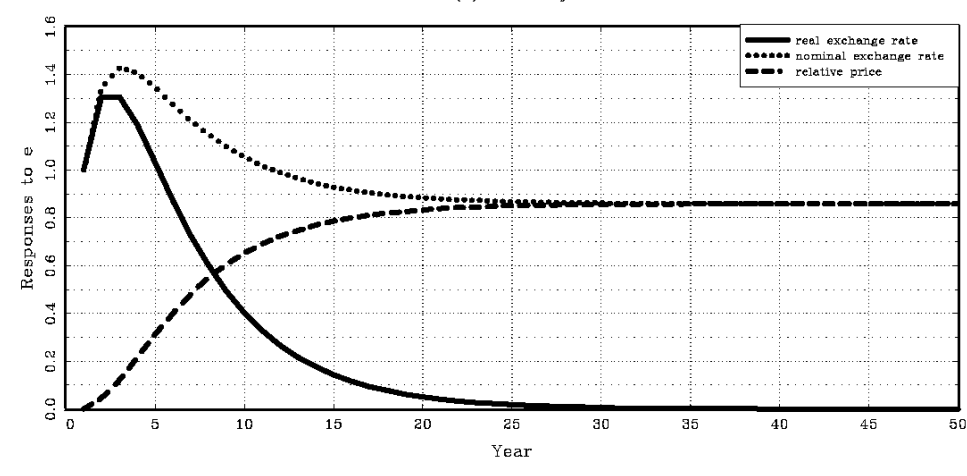

(b) Belgium

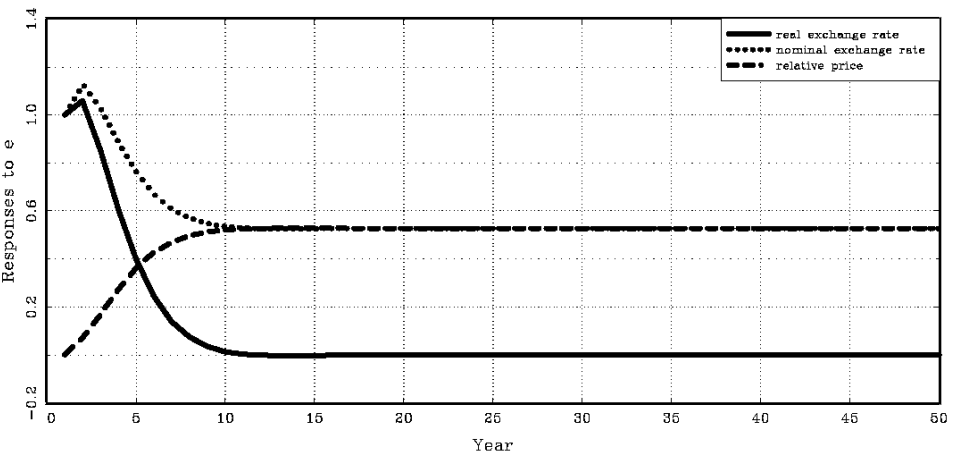

(d) France

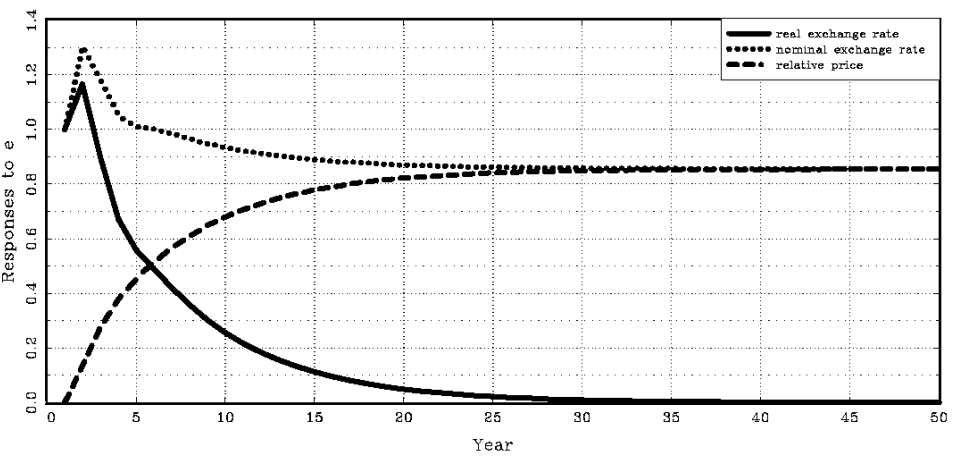

(f) Italy

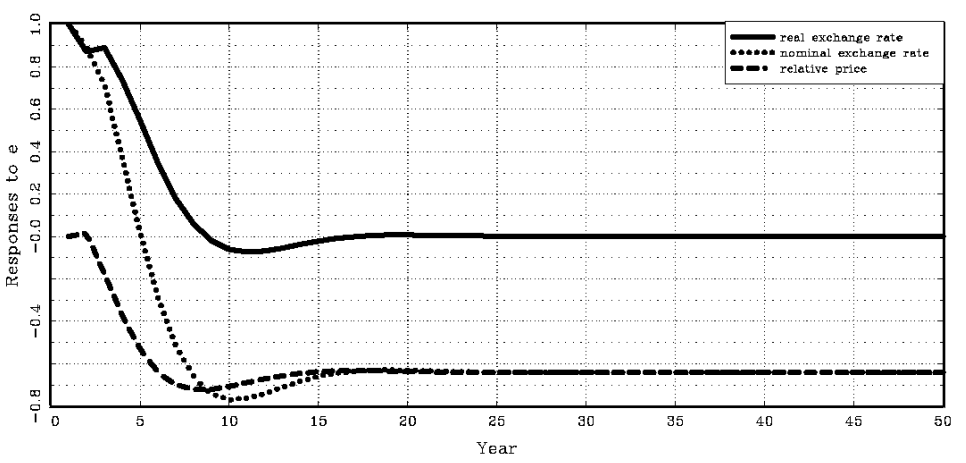


(g) Netherlands

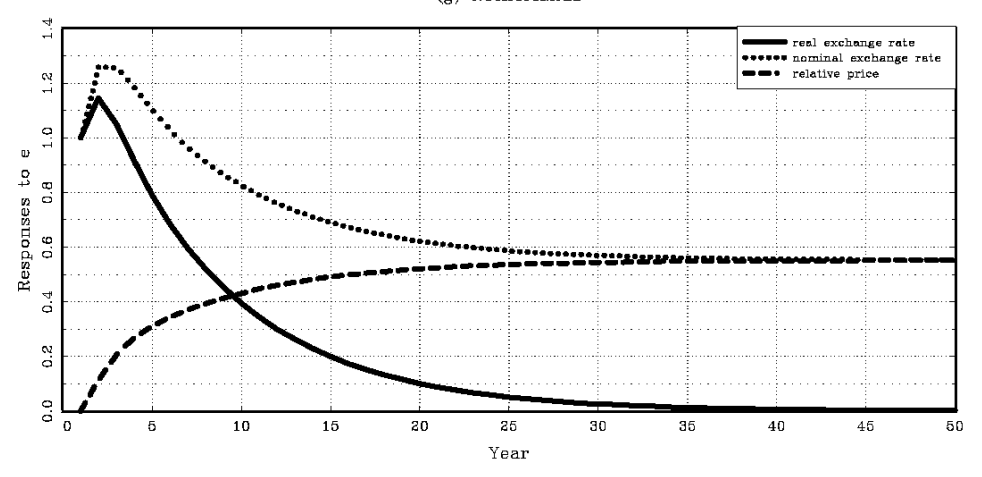

(i) Spain

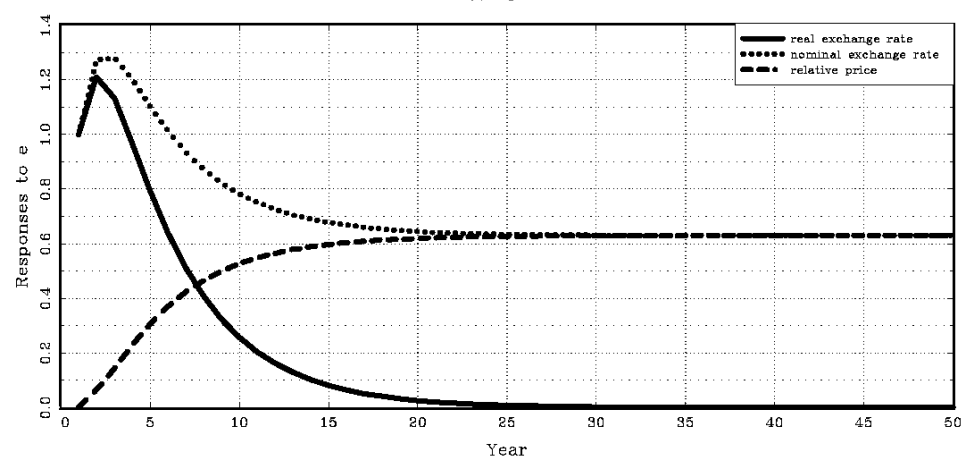

(k) UK

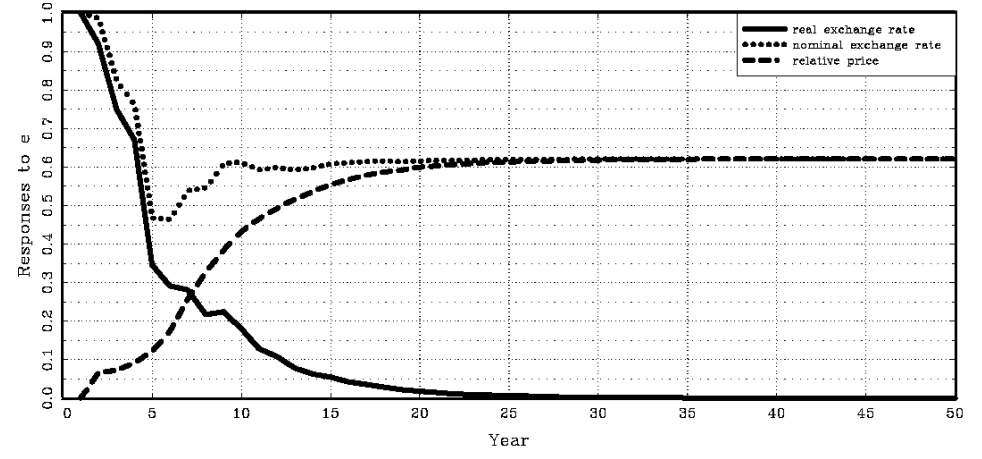

(h) Norway

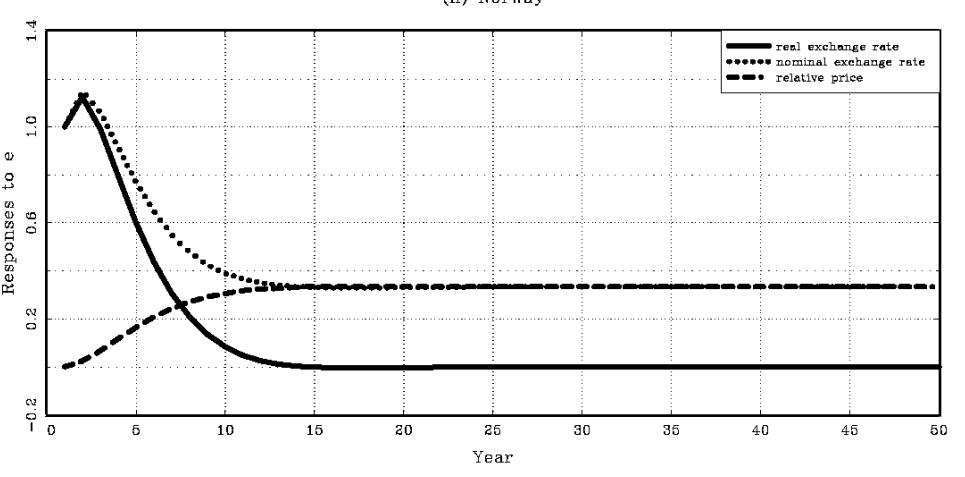

(j) Sweden

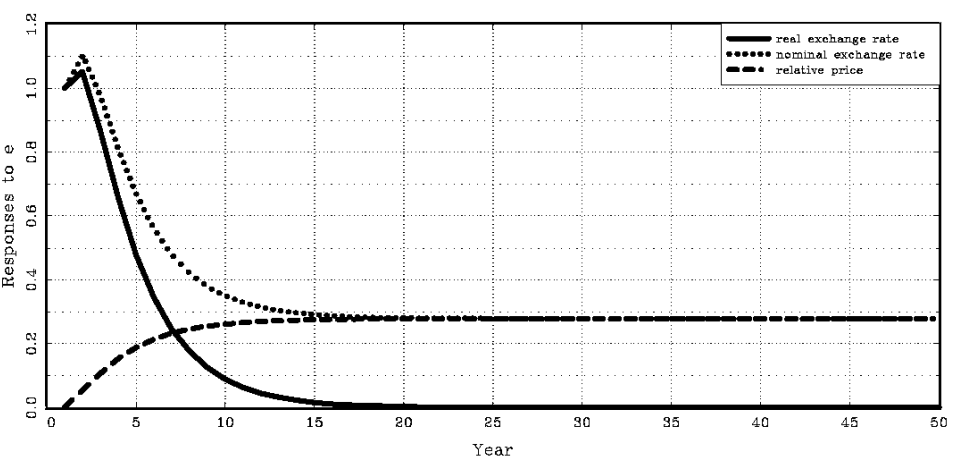

